IRA-International Journal of Education \& Multidisciplinary Studies

ISSN 2455-2526; Vol.04, Issue 01 (2016)

Institute of Research Advances

http://research-advances.org/index.php/IJEMS

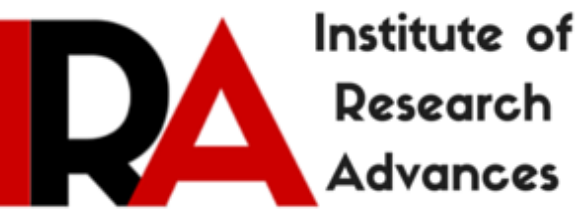

\title{
Love for the rails; Paul Theroux's Travelogues
}

\author{
Neema Susan Mathews \\ Research Scholar, \\ Department of English \\ St Thomas College, Kozhenchery, Kerala, India
}

DOI: http://dx.doi.org/10.21013/iems.v4.n1.p16

\section{How to cite this paper:}

Mathews, N. (2016). Love for the rails; Paul Theroux's Travelogues. IRA International Journal of Education and Multidisciplinary Studies (ISSN 2455-2526), 4(1). doi:http://dx.doi.org/10.21013/jems.v4.n1.p16

(C) Institute of Research Advances

\section{(cc) EY-NC}

This works is licensed under a Creative Commons Attribution-Non Commercial 4.0 International License subject to proper citation to the publication source of the work.

Disclaimer: The scholarly papers as reviewed and published by the Institute of Research Advances (IRA) are the views and opinions of their respective authors and are not the views or opinions of the IRA. The IRA disclaims of any harm or loss caused due to the published content to any party. 


\begin{abstract}
In Paul Theroux's writings railways do not just provide a background or a theme, but become a functional and structural part of their plot and narration. For Theroux railways offer a cross section of a society.The references in his writings are interesting findings in cultural study. The co-travellers create a temporary cultural aura in the compartment. When the narrator involves in conversation with the co-passengers, he acts as a mediator between the readers and the native. A train is both mobile and stationary at the same time. It is mobile for it takes passengers one place to another, at the same time it offers the traveller a stable platform to observe and socialise. Stating the insignificance of destinations, Theroux invites attention to the 'being in a train' experience.
\end{abstract}

Keywords: Travel, trains, social observation, cultural study.

\title{
Introduction
}

When railways were introduced in the nineteenth century, writers in the west received it with varied response. While some accepted the new tempo of modernity, some saw it as the end of art of travel. There was no "adventure" involved in there as it travelled through predetermined paths. Later writers like Charles Dickens, Mark Twain, Harieet Beech Stowe devoted time to reflect on train journeys in their writings. As the railway lines connected more countries- enabling longer journeys-many writers embarked on long expeditions and wrote about them. There happened a growth in travel writings which is based on the specifies of train travel itself. M.M Shoemaker writes on Trans-Siberian Railway and journey on the Orient Express is covered in E.H Cookridge's book, The Orient Express(1980). Later some writers concentrated on the technical aspects of the train, which hardly created any interest in readers. When train no more became the fastest mode of travel, a new genre of travel writing came into being which was pioneered by Paul Theoux, the doyen of American Travel writings.

Travel writing has flourished through the ages, and early travel accounts by explorers and other travellers continue to be valued as a significant source of information about historical cultures and places. Alluring description of intriguing people and vivid landscapes, shocking encounters and narrow escapes, frequent reflection on the process of writing make Paul Theroux a matchless travel writer. The son of a French-Canadian father and an Italian mother, Paul Edward Theroux was born on April 10, 1941 in Medford, Massachusetts. He moved to London in 1972 and embarked on A Grand Tour by train-a journey from London to Tokyo (The Great Indian Bazaar, 1975) and back which mark the beginning of his endless expedition. He has since written a number of other travel books, including descriptions of travelling by train from Boston to Argentina (The Old Patagonian Express, 1979), walking around the United Kingdom (The Kingdom By The Sea, 1983), kayaking in the South Pacific (The Happy Isles Of Oceania, 1992), visiting China (Riding the Iron Rooster, 1988), and travelling from Cairo to Cape Town (Dark Star Safari, 2003).He has published numerous works of fiction, some of which were made into feature films. What distinguishes him from the other writers is that he is also interested in the theoretical aspect of travel writing. He is both practitioner and theoretician of travel literature.

Travelogues or travel narratives have worth beyond mere accounting of occurrences and dates of the journeys conducted by the author. It usually attempts to preserve the essence of the 
place travelled to. Yet a few like Paul Theroux celebrate the journey more than the destination itself. Perhaps, it can be said Theroux wrote about journeys than destinations. Therefore, the mode of travelling is important in his writings. Theroux is famous for his love for the rails. Most of his expeditions are carried out in trains.

What are the reasons that interest Theroux to concentrate on the inside life of a train than the outside geography? This paper attempts to consider three possible reasons that make the writers engaged with the railways and thus throw light on the significance of rails in the writings of Theroux .It may unveil the surprising ways in which technology and culture interact. First reason is the writer's interest in journeys than destinations. Second is to gather elements for a fiction like narrative- to make it readable. And the last is his idiosyncratic love for the rails.

Schivelbusch in his book The Railway journey (1977) talks about general conceptions about railways prevailed in the eighteenth century. Because of the fast movement of the train, a traveller loses his association with the changing landscape and he gets confined in a closed spacegeographical space as Erwin Straus(p. 53) defines. He travels from one place to another by being nowhere. Schivelbusch quotes Ruskin who regarded a traveller as a "mere parcel" as " it matters not you have eyes or are asleep or blind, intelligent or dull, all that you know, at best, of the country you pass is its geographical structure and general clothing" (p. 54). The moving train provides a traveller all the comfort of a safe place while it passes through a foreign country. But it often makes him a less informed traveller. This substantiates Straus' opinion about the lost view of the panoramic and lucid landscape through the train's window. Yet there is something else that these critics disregard-the scene inside. When a traveller is no longer interested in the foreign landscape, he sees the geographical space that a train's compartment offers him as cultural space.

Theroux is a curious traveller. He is more interested in people and in their lives for he declares: "I sought trains; I found passengers" (1975, p. 12). His techniques for getting to know of a culture are observing the local passengers and indulging in conversation with them. He writes in The Tao of Travel: Enlightenments from Lives on the Road (2011):

No mode of transportation inspires me more detailed observation than the railway train. There is no literature of air travel, not much of one bus journeys, and cruise ships inspire social observation (emphasis added) but little less. The train is effective because anyone who cares to can write (as well as sleep and eat) on a train...The rail traveller is often companionable, talkative, even somewhat liberated...such strangers are the best talkers, the best listeners (p. 26).

"Social observation" is the main attraction of a rail journey. While travelling with the local passengers, Theroux observes and understands their way of performance. Christopher Portway observes that, "on a long-distance train as nowhere else one's compartment becomes an observation post of life. Outside there is the everchanging scenario of the world; inside one is amongst people who can become friends, or occasionally enemies, but from whom much knowledge and understanding of the world can be gleaned" (2011, p. 7). The study of culture requires attention to the practices of society in day-today life. It focuses on the life style of the groups of people in a community or civilization. Cultural Studies analyses human experiences considering the assumption that human nature and culture are related. When the narrator involves in conversation with the co-passengers, he acts as a mediator between the readers and the native.

In The Old Patagonian Express Paul Theroux writes:

(y)ears before, I had noticed how trains accurately represented the culture of a country: the seedy distressed country has seedy distressed railway trains, the proud efficient nation 
is similarly reflected in its rolling stock, as Japan is. There is hope in India because the trains are considered vastly more important than the monkey wagons some Indians drive. Dining cars, I found, told the whole story (and if there were no dining cars the country was beneath consideration). The noodle stall in the Malaysian train, the borscht and bad manners on the Trans-Siberian, the kippers and fried bread on the Flying Scotsman (p. 17).

ForTheroux railways offer a cross section of a society.A similar passage we find in The Great Railway Bazaar too, it says:

The State Railway of Thailand is comfortable and expertly run, and now I knew enough of rail travel in Southeast Asia to avoid the air-conditioned sleeping cars, which are freezing cold and have none of the advantages of the wooden sleepers: wide berths and a shower room. There is not another train in the world that has a tall stone jar in the bath compartment, where, before dinner, one can stand naked, sluicing oneself with scoops of water. The trains in any country contain the essential paraphernalia of the culture (emphasis added)... The railway bazaar, with its gadgets and passengers, represented the society so completely that to board it was to be challenged by the national character ( $\mathrm{p}$. 209).

Theroux does not take part in deep cultural transaction. What he intends is to glean the peripheral, as he says, "the essential paraphernalia" of the local culture. The references in his writings are interesting findings in cultural study. A train moves faster than a car or a bus, denying travellers the clear perception of the changing landscape. But allows a traveller to focus inside; either towards themselves or towards the people around. The co-travellers create a temporary cultural aura in the compartment. The writer in the traveller gets insights from this created platform and it forms impressions in his mind. However his findings and his way of judging a culture are strongly critiqued by Debbie Lisle in her The Global Politics of Contemporary Travel Writing (2006). She says the train windows act as a filter that distorts the images that the traveller sees through it (p. 41, 146).

Some of the passages from Theroux prove that a foreigner can get a wrong idea about a local from a moving train. He talks about Turkey, which is 'changeless and harsh . . . a landscape of unheeding devastation' that becomes 'bigger, drier, emptier with repetition ... . [the hills] so sunlit and empty they made my eyes ache' (p. 51, 53, 114). Towards the last hours of the journey he describes the place as 'brown, flat, and treeless, the grimmest landscape I had ever laid eyes on, like an immense beach of frozen dirt washed by an oily black sea'(p. 307-8). Though an outsider, new to the terrain, he doesn't abstain from passing critical judgements on the distanced landscape. His prejudice has earned him much criticism.

Moving on to the next reason, the form of the travelogue has to be considered. Although the early travel accounts were more objective and factual, since modernism major changes have happened to the narrative modalities. Susan Bassnett (2002) emphasizes on this aspect:

In the twentieth century, evidence of a change in the construction of travel narratives can clearly be seen in the stylistic terms. Though the I-narrator still occupies a dominant position, the increasing use of dialogue in travel writing has further closed the gap between travel account and fictions making the travel text resemble the novel much more closely. The protagonist engages in conversations that introduce a range of other characters into the narrative, and the reader is expected to believe that such conversations which apparently transcend any language barrier are recorded rather than invented (235).

Theroux experience as a novelist has taken advantage in the crafting of his travelogues. The traveller has to negotiate between two roles- as a reporter/interpreter and the other as a story teller. He needs stories to maintain the narrative 'literary' rather than factual. Therefore he seeks 
encounters. Theroux mostly uses the narrative mode of 'showing' rather than telling'. "Dialogue", says Carl Thompson in his book, Travel Writing ( 2011), “...will sometimes be rendered directly, as if the writer remembered the exact words spoken in a conversation...(i)nsofar as they utilise such literary devices, travel writer s are arguably not so much reconstructing as constructing their experiences; inevitable what they offer their readers is a somewhat fictionalised rendering of their journeys"(p. 28). On asking why Theroux started travelling, during an interview by Peter Moore(n. d.), he says: I didn't really know what I was doing. But rather than sitting and thinking, writing poetry or book reviews, I decided I was going to go out and search for a story. The idea was simple enough. I'd just leave London, take a train and just keep going. The conceit was getting on a train, then get another train, and then another". His use of dialogues is deliberate for he says:

It was definitely a deliberate decision to put dialogue in. I had always associated travel books with summary, geography, explanations. It was a completely objective experience. Giving the population, statistics, the size of the cities, the texture of the city and so forth and I decided I didn't want to do that. I wanted to write it like a novel (emphasis added). Dialogue. Description. And I'm not objective. I'm full of opinions, many of them probably mistaken. I wanted it to be more like a letter home".

"Write it like a novel", being the ultimate aim of Theroux, Train journeys and characters he meets there provide situations that makes "travel experience" into "travel text" (Thompson, p. 27). The fictive dimension the travelogues possess is the contributions of the experiences he gains on the way. Train's slow pace allows the passengers to interact with each other. Time erases the cultural hindrance between them. This leads to encounters that Theroux desires to happen.

Apart from authorial reasons, Theroux chooses train for his peculiar love for the rails. "Ever since childhood... I have seldom heard a train go by and not wished I were on it", Theroux begins his first travelogue, The Great Railway Bazaar. He continues:

Those whistles sing bewitchment: railways are irresistible bazaars, snaking along perfectly level no matter what the landscape, improving your mood with speed, and never upsetting your drink. The train can reassure you in awful places - a far cry from the anxious sweats of doom airplanes inspire, or the nauseating gas-sickness of the longdistance bus, or the paralysis that afflicts the car passenger (p. 1).

Theroux thinks trains are the best way to navigate through a foreign land: "Train travel animated my imagination and usually gave me the solitude to order and write my thoughts: I have travelled easily in two directions, along the level rails while Asia flashed changes at the window, and at the interior rim of a private world of memory and language. I cannot imagine a luckier combination"(p. 166).

The traveller/writer often has a feeling of alienation in the new/foreign environment, creating notable changes in his/her subject matter. This signifies that there is a mental and physical displacement or dislocation that occurs when the traveller visits a foreign place. To travel in a long distance in train means to have a comfortable -home like -position till the destination. This protective comfort is assured to the writer by their nostalgic, idiosyncratic love for the rails.

A train is both mobile and stationary at the same time. It is mobile for it takes passengers one place to another, at the same time it offers the traveller a stable platform to observe and socialise. But it can differ from person to person. Bill Bryson a contemporary traveller talks in comparison with Theroux that he was never able to be involved in an 'inside life' in a train. He wonders at Theroux's ability to be "immersed in a lively conversation with his fellow passengers". He says - "Quite apart from the consideration that my carriage was nearly empty, I 
don't know how you strike up conversations with strangers in Britain.”(244). Theroux is not bothered about his destination, more than the final destination he looks at the opportunities that have to be exploited on the way.

Decision to travel by train is a matter of aesthetic choice (emphasis added), notes Simon Ward, which is very true in the case of Paul Theroux. "If a train is large and comfortable you don't even need a destination; a corner seat is enough, and you can be one of those travellers who stay in motion, straddling the tracks, and never arrive or feel they ought to"(1), writes Theroux in The Great Railway Bazaar. He talks about the insignificance of destinations here, inviting attention to the 'being in a train' experience. In a globalised world where inconveniences-which caters to the subject matter of travelogues- are vanishing, Theroux's writings find place in the reading realm with its trajectory of danger and discovery. He takes trains from London to Japan in The Great Railway Bazaar, paddles across atolls in The Happy Isles of Oceania(1992), and returns to the railroad to travel from Cairo to Cape Town in Dark Star Safari (2003).Railways do not just provide a background or a theme, but become a functional and structural part of their plot and narration in his writings.

\section{References}

1. Bassnet, S. (2002). "Travel Writing and Gender.". In The Cambridge companion to travel writing. Cambridge, U.K.: Cambridge University Press.

2. Lislie, Debbie. The Global Politics of Contemporary Travel Writing. New York: Cambridge University Press, 2006

3. Paul Theroux: 'How I write travel books' [Interview by P. Moore]. (n.d.). In Wanderlust Travel Magazine. Retrieved July 20, 2016, from http://www.wanderlust.co.uk/magazine/articles/interviews/paul-theroux-how-i-writetravel-books?page $=$ all

4. Portway, C. (2001). The world commuter: Great journeys by train. Chichester: Summersdale

5. Schivelbusch, W. (2014). The railway journey: The industrialization of time and space in the nineteenth century. Oakland: The University of California Press. Retrieved July 20, 2016, from

https://www.google.co.in/url?sa=t\&rct=j\&q=\&esrc=s\&source=web\&cd=2\&cad=rja\&uac $\mathrm{t}=8 \& \mathrm{ved}=0 \mathrm{ahUKEwi0kYCGg5XOAhVBM} 48 \mathrm{KHWGYBCgQFggiMAE \& url=https://boo}$ ks.google.com/books/about/The Railway Journey.html?id=890nCC kZeIC\&usg=AFQj CNGzB2xSzFkJrVc4F3mKaUuJy24CgA\&sig2=29crgDOT

6. Simon, W. (2003). Trains in Literature of travel and exploration: An encyclopedia(J. Speake, Ed.). Retrieved July 18, 2016, from https://books.google.co.in/books?id=lCUzXMay4oC\&pg=PA1192\&lpg=PA1192\&dq=Li terature of Travel and Exploration R to Z. train\&source=bl\&ots=Is4ciIeDre\&sig=l_qusZZ97K7kzGz4filAie_aNE8\&hl=en\&sa=X\& ved=0ahUKEwj828_4uZLOAhUIPo8KHcx9CRYQ6AEIHTAA\#v=onepage \&q=Literatu re of Travel and Exploration R to Z. train\&f=false

7. Theroux, P. (2008). The Great Railway Bazaar. England: Penguin Classics.

8. Theroux, P. (2008). The Ol d Pantagonian Express. England: Penguin Classics.

9. Theroux, P. (2011). The Tao of Travel: Enlightenments from lives on the road. Boston:

Houghton Mifflin Harcourt.

10. Thompson, Carl. Travel Writing. London: Routledge, 2011. 